\title{
EFFECTS OF A MANDATORY SAFETY BELT LAW ON HOSPITAL ADMISSIONS
}

\author{
AleXANDER C. WAgenaAR \\ University of Minnesota, School of Public Health, Division of Epidemiology, Minneapolis, \\ MN 55455 U.S.A. \\ and \\ LEWIS H. MARGOLIS \\ University of Michigan, School of Public Health, Department of Public Health Policy and \\ Administration, Ann Arbor, MI 48109 U.S.A.
}

(Received 3 July 1989; in revised form 13 November 1989)

\begin{abstract}
Although the effectiveness of automobile safety belts in reducing risk of serious injury in traffic crashes is well documented, safety belt use in many U.S. jurisdictions remains low. Michigan's mandatory safety belt law for front-seat occupants, implemented in July 1985, is one of 34 similar laws in the United States intended to increase belt use and reduce crash-related injuries. Using time-series intervention analyses of data from 14 hospitals throughout the state, we found a $19 \%$ reduction in the rate of admitted patients for all automobile occupant injuries and a $20 \%$ reduction in the rate of admitted patients with extremity injuries following implementation of the safety belt law. The utility of hospital data for the evaluation of interventions like the safety belt law reinforce the importance of consistently recording E-codes for all injury patients.
\end{abstract}

\section{INTRODUCTION}

When properly used, automobile safety belts reduce the risk of death or serious injury in motor vehicle crashes by at least 40 percent (Rutherford et al. 1985; Barancik et al. 1986; Evans 1986; Orsay et al. 1988). The main factor limiting the public health benefits of this technology has been low rates of belt use among drivers and passengers. To increase belt use, 34 states and the District of Columbia in the United States and numerous other countries have implemented compulsory belt use laws, usually focused on drivers and front-seat passengers. Significant increases in safety belt use and decreases in motor vehicle crash fatalities are typically associated with such laws; Wagenaar and others (1988) recently reviewed this literature. The State of Michigan implemented compulsory safety belt use for front-seat motor vehicle occupants beginning July 1, 1985 . The law permits secondary enforcement only; that is, a motorist must first be stopped for some other infraction before a citation for failure to use safety belts can be issued.

Most studies of compulsory belt use policies in the United States and elsewhere focus on the effects of the laws on traffic fatalities, since mortality data are readily available (Wagenaar et al. 1988). A smaller number of studies focus on the effects of the laws on injuries, using data from police crash reports (Chorba et al. 1988; Reinfurt et al. 1987). Police reports are limited by definitions of injury that are not based on clinical or anatomical criteria, but solely on severity as perceived by the officer at the scene of the crash. Hospital-based studies are typically limited to one or a few hospitals in a single area, minimizing the size and representativeness of the sample analyzed and increasing the importance of replication with other samples. Our objective in the current study was to examine the effects of a compulsory safety belt use law on injuries seen at hospitals throughout the State of Michigan.

\section{METHODS}

\section{Data collection}

Records on all hospital admissions in Michigan between January 1980 and October 1986 were obtained from the Michigan Health Data Corporation, which abstracts from 
medical records variables such as age of patient, admission and discharge dates, primary and secondary diagnoses, and others. To control for the time lag between admission and discharge, only patients admitted through October 1986 were included in our analyses, because none of them were still hospitalized at the end of 1986, and the full complement of discharge database information was available. For years before 1986, patients admitted during one year and discharged the next were assigned to their admission year in order to calculate accurate rates. In short, although these data were obtained as a discharge database, we created an admissions database to analyze cases by the month the event precipitating the injury occurred.

Because up to seven diagnoses were abstracted from hospital records for the database, we had data on both the ICD-9 N-code (clinical nature of injury) as well as the E-code (cxtcrnal cause of injury). Only patients whose primary diagnosis indicated an injury were included in our analyses; over $90 \%$ of patients with an $\mathrm{N}$-code indicating an injury had the injury recorded as the primary diagnosis. Unfortunately, only about $10 \%$ of all injury $\mathrm{N}$-codes in the state had an accompanying E-code. Examination of the distribution of E-codes by hospital revealed a subset of 14 hospitals that consistently recorded E-codes on over $80 \%$ of their injury admissions throughout the seven-year period under study. Subsequent analyses were based on the records of these 14 hospitals, geographically distributed across the state, including five large urban hospitals, two small rural hospitals, and seven intermediate hospitals. Ten of the 14 hospitals share catchment areas with a total of 26 other hospitals. Motor vehicle related fatalities that occurred before admission have not been included in these analyses. Barancik and others (1986) have demonstrated that fatalities (pre- or post- admission) are small in number compared to nonfatal motor vehicle injuries. Therefore, exclusion of preadmission fatalities has little impact on overall injury rates. ${ }^{*}$

The catchment areas covered by the 14 hospitals appear representative of the state as a whole, because three demographic characteristics associated with health and injury outcomes in the areas studied are similar to statewide figures. The percentage of the population in the urban areas is $69.2 \%$ for the catchment areas under study and $70.1 \%$ for the entire state. Similarly, $13.8 \%$ of the population in the catchment areas is college educated vs. $14.2 \%$ for the state, and $7.6 \%$ of the population in the catchment areas is below the poverty level vs. $10.4 \%$ in the state (Verway 1986-1987). Nevertheless, it remains possible that the study hospitals differed from those not consistently recording E-codes. The proportion of all injury hospitalizations in the catchment areas admitted to the 10 sample hospitals remained constant throughout the 1980-1986 period (Fig. 1). Thus, our analyses do not appear to be confounded by a change in referral patterns.

Patients analyzed were further restricted to those whose injuries could have been affected by the use of safety belts. Thus, we excluded the following E-codes: $(i)$ any E810 through E819 code with a .2 through .8 fourth digit, which represent motorcyclists, streetcars, riders of animals, bicyclists, and passengers of miscellaneous vehicles; and (ii) E817, which represents an injury associated with boarding or alighting from a motor vehicle. Injury outcomes were grouped into six anatomic regions: head, neck, back, thorax, abdomen, and extremities. A seventh category included patients with injuries for which no body part was mentioned in the medical record. $\dagger$ The final sample consisted of 8,661 patients 16 years old and over with injuries incurred as a motor vehicle occupant and admitted to the 14 hospitals over the seven-year period. Children under age 16 were excluded because of concerns about the effectiveness of safety belts for children (Agran et al. 1987).

The number of people injured in motor vehicle crashes is largely determined by the number of vehicles involved in crashes. In Michigan, the number of crash-involved vehicles increased substantially from 1983 through 1986 (Fig. 2). This upward trend was due to increases in the number of miles traveled (Fig. 3), economic cxpansion as reflected

*Analyses of effects of the Michigan safety belt law on fatalities have been reported previously (Streff et al. 1990)

+Complete lists of $\mathrm{N}$-codes for each category are available from the authors. 


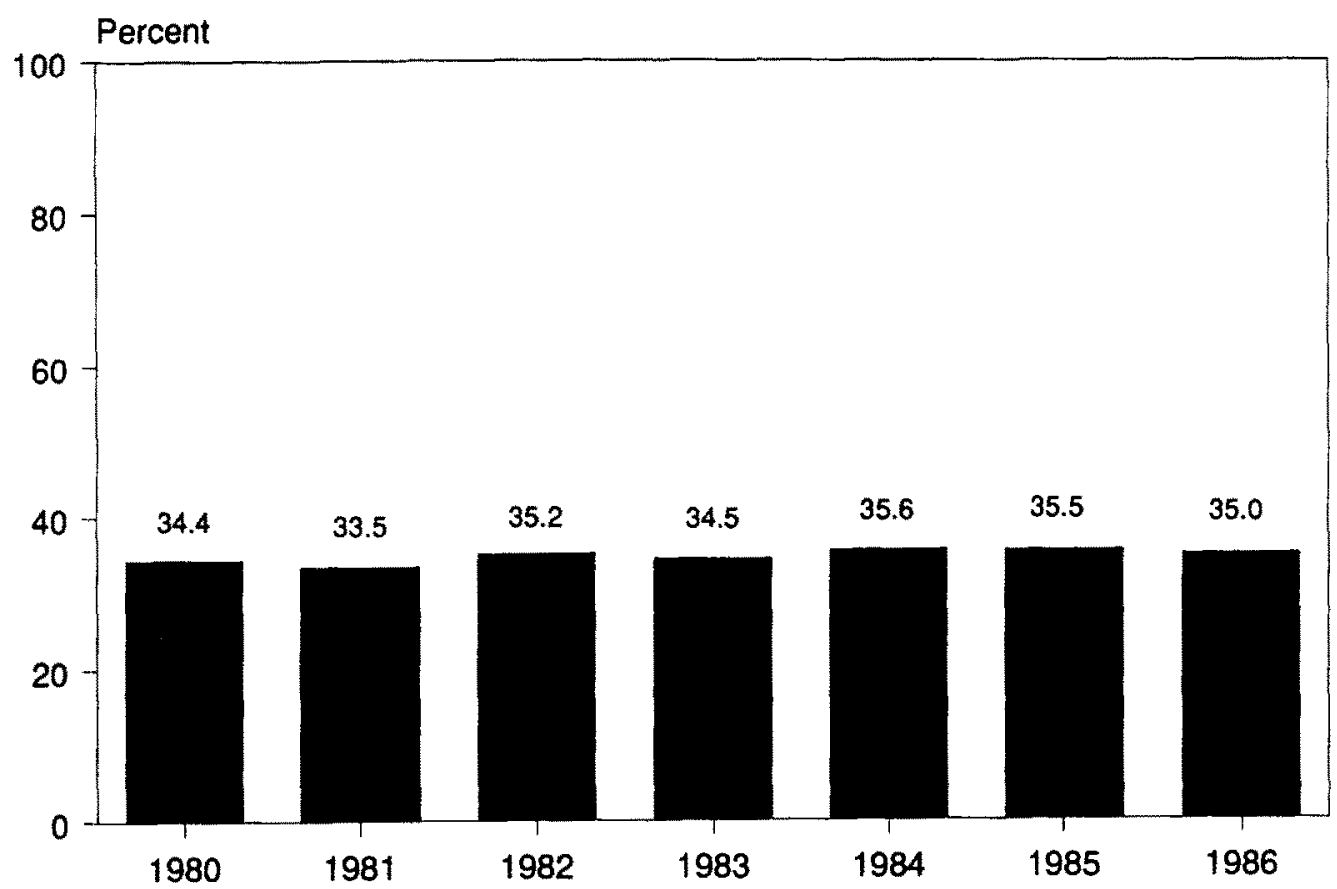

Fig. 1. Percent of all catchment area injury admissions accounted for by sample hospitals, 1980-1986.

in lower rates of unemployment (Fig. 4), and other factors. The literature of the multiple determinants of the aggregate number of crashes is beyond the scope of this paper [see Wagenaar (1984) and Wagenaar and Streff (1989) for discussion of some of these issues]. Our objective here was simply to control for such broader trends when assessing the effects of laws requiring safety belt use. Safety belt laws are designed to reduce the probability of injury given a crash by increasing the proportion of motorists protected by safety belts. They are not expected to substantially affect the number of vehicles

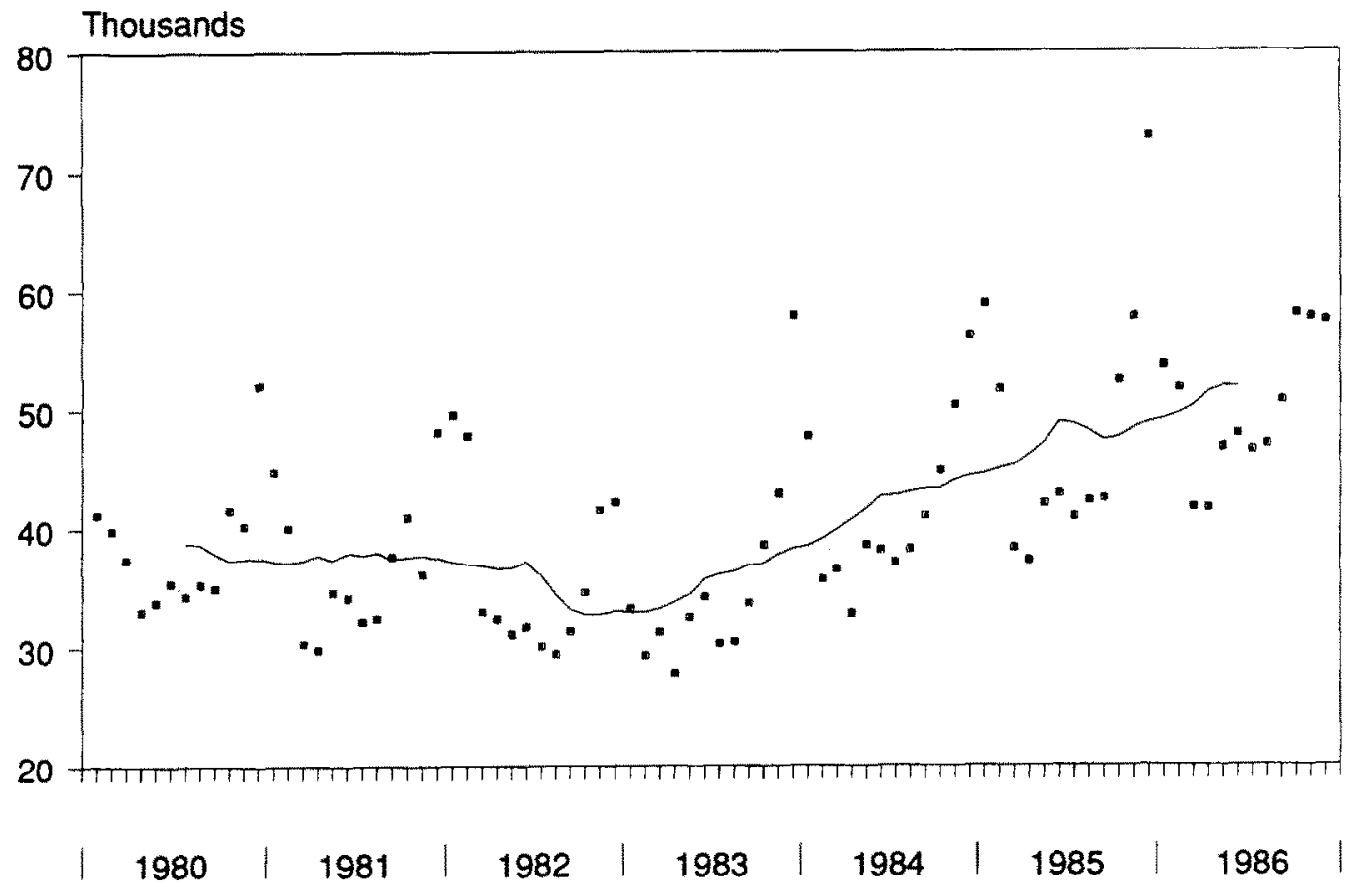

Fig. 2. Number of crash-involved vehicles per month in Michigan, 1980-1986. 


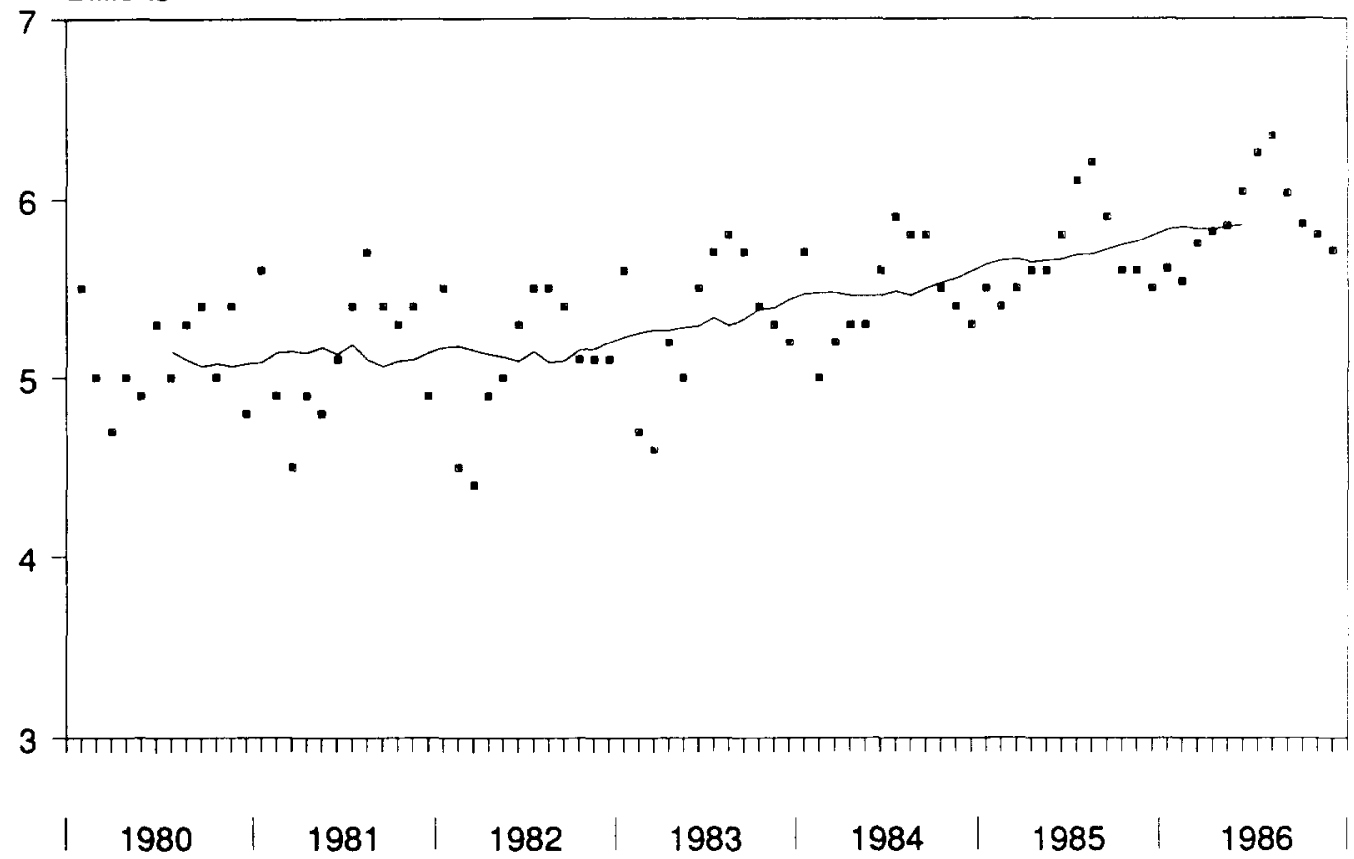

Fig. 3. Number of vehicle miles traveled per month in Michigan, 1980-1986.

involved in crashes. To control for the effects of changes in the number of crash-involved vehicles, we analyzed crash-adjusted rates of injuries, as well as the raw frequency of injuries. Because accurate data on the number of crashes by month were not available specifically for each catchment area under study, the figures for the entire state were used. Since, as noted above, the catchment areas are similar to the state as a whole on major demographic variables, it is not unreasonable to assume that changes in overall crash involvement in the areas under study are similar to statewide changes.

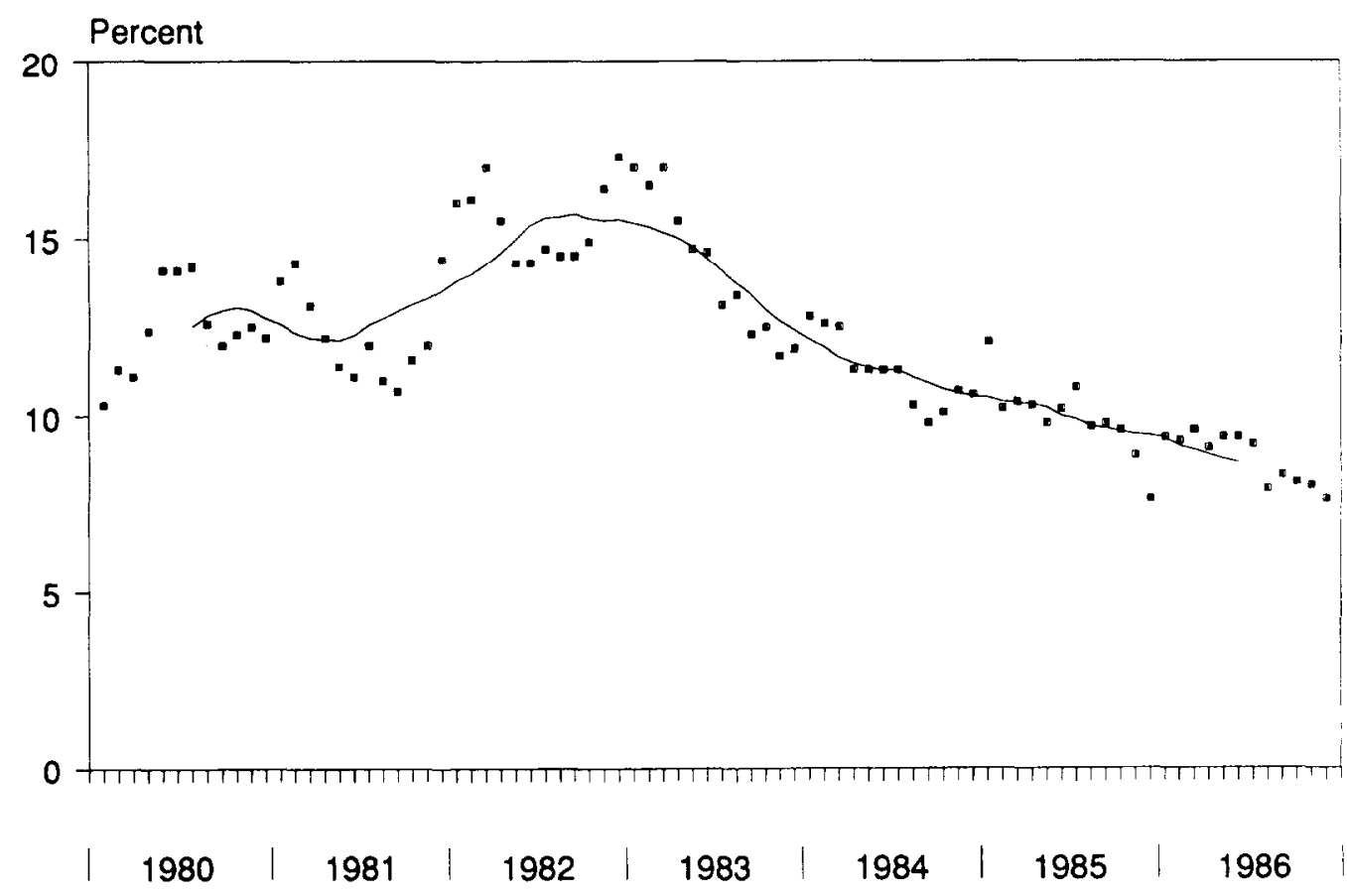

Fig. 4. Unemployment rate in Michigan, 1980-1986. 
Analyses

We used Box-Jenkins time-series modeling methods (Box and Jenkins 1976; Box and Tiao 1975). Autoregressive integrated moving average models were developed iteratively, repeatedly going through cycles of specifying a model, estimating it, and evaluating its adequacy in terms of accounting for all significant autocorrelation patterns in the series. Data were log transformed to reduce the degree to which the variance of the dependent variable changes over time (i.e. reduce heteroscedasticity). Final models had significant noise model parameters, low correlations among parameters, and insignificant residual autocorrelations. Because belt use increased abruptly in Michigan at the time the belt law took effect (Wagenaar and Wiviott 1986), intervention step functions were added to each baseline model to estimate the significance and magnitude of changes in rate of injuries beginning the first month the law took effect. Because the models were intrinsically nonlinear, the Gauss-Marquardt backcasting algorithm was used to estimate the parameters (Dixon et al. 1983). To improve interpretability of the parameters in the logarithm metric, results were converted to an estimated percentage change in injuries occurring after the safety belt law from levels expected given baseline patterns, using $\left(\mathrm{e}^{\omega}-1\right) 100$, where $\omega$ is the parameter estimate from each time-series model.

\section{RESULTS}

A significant $19.3 \%$ decline in the crash-adjusted rate of injuries requiring hospitalization occurred at the time the safety belt law was implemented. When the crashadjusted rate of hospitalized injuries was stratified by body region injured, time-series model estimates were consistently negative, although only the $20.4 \%$ reduction in extremity injuries was statistically significant. The relatively small number of cases within each subcategory and the considerable random fluctuation from month to month and year to year in the incidence of injuries result in large standard errors around the timeseries model intervention effect estimates (Table 1). Nevertheless, the point estimates, with the sole exception of thoracic injuries, range from -11 to $-20 \%$.

Two measures of injury severity that were available provided additional indicators of the effectiveness of the law. Analyses by length of hospital stay (low $=0$ to 2 days; medium $=3$ to 6 days; high -7 or more days) showed a significant $43 \%$ decline in crash-adjusted rate of hospitalizations of a week or more. Low and medium length-ofstay hospitalizations did not change significantly (Table 1). Consistent with the results stratified by length of stay, the crash-adjusted rate of hospitalizations with special care unit use also declined (although not statistically significant; see Table 1). These results are consistent with the hypothesis that crash-related injuries are less severe after implementation of the safety belt law. Although financial incentives have created clear pressures to reduce length of stay and special care unit use in recent years (Schramm and Gabel 1988), the decline in average length of stay in Michigan over the entire sevenyear period studied was small compared to the substantial decline in long length-of-stay crash-related hospitalizations that began the exact month the safety belt law took effect (Wolfe et al. 1989).

The $22 \%$ decline in rate of injuries among persons of color is noteworthy for two reasons. First, the proportion using safety belts increased markedly after the law came into effect. Second, belt use among persons of color in Michigan remains lower than the population in general, a fact that suggests targeting of educational and other interventions to increase use.

\section{DISCUSSION}

This study highlights use of hospital discharge data to complement police crash reports and emergency room registries in evaluating the effects of safety belt laws. Following the implementation of a mandatory safety belt law in Michigan, crash-adjusted motor-vehicle-related admissions declined by $19.3 \%$. The crude frequency of admissions during the period under study increased by $7 \%$ in 1985 when the belt law was imple- 
Table 1. Effects of Michigan's compulsory safety belt law: Results from time-series intervention models

\begin{tabular}{|c|c|c|c|c|c|c|c|}
\hline \multirow[t]{2}{*}{ Injury } & \multirow[t]{2}{*}{$\begin{array}{l}\text { ARIMA } \\
\text { model }\end{array}$} & \multirow[t]{2}{*}{$\begin{array}{l}\text { Ljung-Box } \\
\text { Q-statistic }^{\mathrm{a}}\end{array}$} & \multirow[t]{2}{*}{$\begin{array}{l}\text { Adjusted } \\
\text { R-square }\end{array}$} & \multirow[t]{2}{*}{$\begin{array}{c}\text { Time-series } \\
\text { estimate }\end{array}$} & \multirow[t]{2}{*}{$\begin{array}{l}\text { Percent } \\
\text { change }\end{array}$} & \multicolumn{2}{|c|}{$\begin{array}{l}90 \% \text { confidence } \\
\text { interval }\end{array}$} \\
\hline & & & & & & Lower & Upper \\
\hline \multicolumn{8}{|l|}{ Head } \\
\hline Frequency & $(0,0,1)(0,0,1)_{15}$ & 14 & 0.06 & -0.00 & -0.21 & -10.85 & 11.69 \\
\hline Rate & $(0,1,1)(0,0,1)_{6}$ & 26 & 0.27 & -0.14 & -13.08 & -32.50 & 11.92 \\
\hline \multicolumn{8}{|l|}{ Neck } \\
\hline Frequency & $(0,0,1)(0,0,0)_{12}$ & 27 & 0.02 & 0.14 & 15.34 & -7.34 & 43.57 \\
\hline \multirow{2}{*}{\multicolumn{8}{|c|}{ Back }} \\
\hline & & & & & & & \\
\hline Frequency & $(0,0,0)(0,1,1)_{12}$ & 20 & 0.00 & -0.02 & -2.41 & -20.87 & 20.36 \\
\hline Rate & $(0,0,0)(0,0,0)_{12}$ & 24 & 0.02 & -0.27 & -23.81 & -39.54 & -3.98 \\
\hline \multicolumn{8}{|l|}{ Thorax } \\
\hline Frequency & $(0,0,2)(0,0,0)_{12}$ & 15 & 0.11 & 0.27 & $30.72^{*}$ & 13.61 & 50.41 \\
\hline Rate & $(0,0,0)(0,0,0)_{12}$ & 17 & 0.00 & -0.01 & -0.97 & -16.41 & 17.31 \\
\hline \multicolumn{8}{|l|}{ Abdomen } \\
\hline Frequency & $(0,0,1)(0,0,1)_{10}$ & 25 & 0.19 & 0.15 & 16.08 & 1.41 & 32.86 \\
\hline Rate & $(0,0,0)(0,0,0)_{12}$ & 28 & 0.04 & -0.16 & -14.48 & -32.27 & 7.99 \\
\hline \multicolumn{8}{|l|}{ Extremity } \\
\hline Frequency & $(4,0,0)(0,0,0)_{12}$ & 25 & 0.07 & 0.05 & 5.43 & -3.97 & 15.76 \\
\hline Rate & $(0,0,0)(0,1,1)_{12}$ & 28 & 0.29 & -0.23 & $-20.38^{*}$ & -28.38 & -11.48 \\
\hline \multicolumn{8}{|l|}{ Total } \\
\hline Frequency & $(0,0,1)(0,0,0)_{12}$ & 33 & 0.07 & 0.07 & 7.17 & -1.83 & 16.99 \\
\hline Rate & $(0,0,2)(0,1,1)_{12}$ & 20 & 0.49 & -0.21 & $-19.31^{*}$ & -27.16 & -10.62 \\
\hline \multicolumn{8}{|c|}{ Low length of stay } \\
\hline Frequency & $(0,1,1)(0,0,1)_{12}$ & 24 & 0.37 & 0.15 & 16.42 & -1.73 & 37.91 \\
\hline Rate & $(0,0,1)(0,1,1)_{12}$ & 25 & 0.26 & 0.06 & 6.42 & -3.86 & 17.81 \\
\hline \multicolumn{8}{|c|}{ Medium length of stay } \\
\hline Frequency & $(0,0,1)(0,1,1)_{12}$ & 25 & 0.00 & 0.05 & 5.25 & -5.05 & 16.67 \\
\hline Rate & $(0,1,1)(0,0,0)_{12}$ & 22 & 0.28 & 0.22 & 25.03 & -12.08 & 77.82 \\
\hline \multicolumn{8}{|c|}{ High length of stay } \\
\hline Frequency & $(0,0,2)(0,1,1)_{12}$ & 19 & 0.27 & -0.28 & $-24.07^{*}$ & -32.80 & -14.19 \\
\hline Rate & $(0,0,2)(0,1,1)_{12}$ & 17 & 0.52 & -0.56 & $-42.99^{*}$ & -52.18 & -32.03 \\
\hline \multicolumn{8}{|c|}{ With special care unit use } \\
\hline Frequency & $(0,0,0)(0,0,0)_{12}$ & 21 & 0.00 & 0.08 & 8.81 & -11.62 & 33.96 \\
\hline Rate & $(0,0,0)(0,0,0)_{12}$ & 25 & 0.33 & -0.18 & -16.51 & -32.65 & 3.50 \\
\hline \multicolumn{8}{|c|}{ Without special care unit use } \\
\hline Frequency & $(0,0,2)(0,1,1)_{12}$ & 22 & 0.31 & 0.07 & 7.43 & -0.14 & 15.57 \\
\hline Rate & $(0,1,6)(0,0,0)_{12}$ & 21 & 0.33 & -0.07 & -6.64 & -29.31 & 23.31 \\
\hline \multicolumn{8}{|l|}{ Male } \\
\hline Frequency & $(0,0,6)(0,1,1)_{12}$ & 27 & 0.20 & 0.08 & $8.04^{*}$ & 1.85 & 14.62 \\
\hline Rate & $(0,1,3)(0,0,0)_{12}$ & 28 & 0.31 & -0.15 & -13.64 & -30.01 & 6.54 \\
\hline Female & & & & & & & \\
\hline Frequency & $(0,1,4)(0,0,0)_{12}$ & 22 & 0.06 & 0.166 & 6.18 & -9.60 & 24.72 \\
\hline Rate & $(0,1,1)(0,0,1)_{4}(0,0,1)_{6}$ & 22 & 0.23 & -0.10 & -9.33 & -27.32 & 13.10 \\
\hline White & & & & & & & \\
\hline Frequency & $(0,0,5)(0,1,1)_{12}$ & 30 & 0.28 & 0.03 & 2.99 & -2.31 & 8.58 \\
\hline Rate & $(0,1,6)(0,0,0)_{12}$ & 29 & 0.43 & -0.22 & -19.08 & -34.46 & -1.15 \\
\hline Persons of col & & & & & & & \\
\hline Frequency & $(0,0,0)(0,0,0)_{12}$ & 20 & 0.00 & 0.02 & 2.08 & -16.05 & 24.13 \\
\hline Rate & $(0,0,0)(0,0,0)_{12}$ & 16 & 0.01 & -0.24 & $-21.65^{*}$ & -35.95 & -4.16 \\
\hline
\end{tabular}

${ }^{3}$ Ljung and Box 1976

*Significant at $p<.05$

mented, consistent with an economic expansion, increased travel mileage, and increased numbers of vehicles involved in crashes.

Consistent with other hospitalized patient samples (Rutherford et al. 1985; States et al. 1986), injuries to the head and extremities were the most frequent in our sample. Although we found an unambiguous decline in rate of extremity injuries, the decline in rate of head injuries was not significant. No significant decrease in the number or rate of head injuries may be due to the fact that head impacts with the steering wheel cause injuries, even when drivers are belted. The number of cases in our sample is insufficient to stratify by severity to determine whether the frequency of head injuries of particular severity levels has changed. Investigators to date have reported declines (States et al. 1986) and increases (Rutherford et al. 1985) in severe head injuries associated with safety belt use laws. Further research is needed to isolate the specific effects of safety belt laws on particular types of head injuries.

This study has significant limitations, all related to the need to limit our analyses to the 14 sample hospitals with adequate E-coding (out of 243 hospitals in the state). First, the lack of desired precision in the time-series model estimates of specific injuries 
resulted from the smaller monthly counts of admitted patients. A census of all injured patients would permit additional breakdowns by the nature of the injury, helping to isolate mechanisms for the beneficial effects of the law. Availability of E-codes for all injury admissions in the state would permit straightforward calculations of injury rates per population, per licensed driver, per vehicle mile traveled, or per crashed vehicle, obviating the need for assumptions concerning the representativeness of catchment areas covered by sample hospitals. Health care professionals who serve on hospital record committees should insist that proper medical record-keeping for hospitals and other emergency facilities include the recording of E-codes. Finally, studies such as that reported here will benefit from the continued development of algorithms for determining injury severity based on $\mathrm{N}$-codes and routine recording of injury severity (e.g. Abbreviated Injury Scale or Injury Severity Score) (MacKenzie et al. 1986).

There are two main ways in which further advances in the protection of crashinvolved motor vehicle occupants can be achieved: (1) increasing the proportion of motorists consistently using safety belts, and (2) improving the design of vehicles to lower the probability of injury or death given a crash. Studies suggest that compliance with mandatory safety belt laws is related both to the intensity with which such laws are enforced and to specific provisions of the laws (Jonah and Grant 1985; Williams et al. 1987). For example, primary rather than secondary enforcement is likely to increase the proportion of motorists using belts. There is also need for continued improvements in the design of safety belts and other vehicle features to reduce injuries.

Increased belt use in Michigan was not associated with a reduction in the number or rate of thoracic injuries. One could plausibly argue that increased safety belt use would not necessarily affect the overall rate of thoracic injuries and might even increase their number. Rutherford and associates (1985) found an increase in injuries to the sternum, because of contact with the steering column or shoulder belt, following Great Britain's implementation of compulsory safety belt use. Since implementation of compulsory use, some thoracic injuries to occupants who would have been unbelted without the law may have been prevented by belt use. But other thoracic injuries may occur to crash-involved occupants who are now belted, but who would have been killed without belts. Crash forces without belt use may cause impacts with the head, neck, thorax, abdomen, and extremities. With belt use, crash forces are often concentrated on the thorax. Crash-involved occupants who had been converted by the law from nonusers to users of safety belts may have traded severe injuries leading to long-term disability (e.g. head or neck injuries) for thoracic injuries, which lead to permanent disability only in severe cases. Thoracic injuries among belted occupants could be reduced by means of improved design of safety belts, such as elimination of belts that do not automatically retract after an occupant moves forward loosening the belt, and inclusion of pre-tensioners that tighten the belt immediately at crash impact (Viano 1988). Finally, standard installation of airbag restraint systems in all cars would not only provide additional protection from thoracic and other injuries among belted occupants, but would provide substantial protection to those occupants who refuse to use safety belts despite a compulsory use law (Backaitis and Roberts 1987).

Acknowledgments - We express our appreciation to Wanda Liu, Charles Compton, and Phil Tedeschi who assisted with data file management and analyses. Thanks to the two anonymous reviewers who provided helpful comments. This study was funded in part by the U.S. National Highway Traffic Safety Administration and the Michigan Office of Highway Safety Planning. An earlier version of this paper was presented at the First World Conference on Accident and Injury Prevention, Stockholm, Sweden, September 17-20, 1989.

\section{REFERENCES}

Agran, P.; Dunkle, D.; Winn, D. Injuries to a sample of seatbelted children evaluated and treated in a hospital emergency room. J. Trauma. 27:58-64; 1987.

Backaitis, S. H.; Roberts, J. V. Occupant injury patterns in crashes with airbag equipped government sponsored cars. 31st Stapp Car Crash Conference Proceedings. Warrendale, PA: Society of Automotive Engineers; $1987 ; 251-258$.

Barancik, J. I.; Chatterjee, B. F.; Greene-Cradden, Y. C.; Michenzi, E. M.; Kramer, C. F.; Thode, H.; Fife, 
D. Motor vehicle trauma in northeastern Ohio, I: Incidence and outcome by age, sex, and road-use category. Am. J. Epidemiol. 123:846-861; 1986.

Box, G. E. P.; Jenkins, G. M. Time series analysis: Forecasting and control. Rev. Ed. San Francisco: HoldenDay; 1976.

Box, G. E. P.; Tiao, G. C. Intervention analysis with applications to economic and environmental problems. J. Am. Stat. Assoc. 70:70-79; 1975 .

Chorba, T. L.; Reinfurt, D.; Hulka, B. S. Efficacy of mandatory seat-belt use legislation. JAMA. 260:35933597; 1988.

Dixon, W. J.; Brown, M. B.; Engelman, L.; Frane, J. W.; Hill, M. A.; Jennrick, R. I.; Toporek, J. D. BMDP statistical software: 1983 printing with additions. Los Angeles: University of California Press; 1983.

Evans, L. The effectiveness of safety belts in preventing fatalities. Accid. Anal. Prev. 18:229-241; 1986.

Jonah, B. A.; Grant, B. A. Long-term effectiveness of selective traffic enforcement programs for increasing seat belt use. J. Appl. Psychol. 70:257-263; 1985.

Ljung, G.; Box, G. E. P. Studies in the modeling of discrete time series 3: A modification of the overall chisquare test of lack of fit in time series model. Technical Report 477. Madison: University of Wisconsin, Department of Statistics; 1976.

MacKenzie, E. J.; Steinwachs, D. M.; Shankar, B. S.; Turney, S. Z. An ICD-9CM to AIS conversion table: Development and application. In: 30th Annual Proceedings of the American Association for Automotive Medicine. Arlington Heights, IL: American Association for Automotive Medicine; 1986.

Orsay, E.; Turnbull, T. L.; Dunne, M.; Barrett, J. A.; Langenberg, P.; Orsay, P. Prospective study of the effect of safety belts on morbidity and health care costs in motor-vehicle accidents. JAMA. 260:3598-3603; 1988.

Reinfurt, D. W.; Campbell, B. J.; Hunter, W. W.; Stutts, J. C. An evaluation of North Carolina's occupant restraint law. In: 31st Annual Proceedings American Association for Automotive Medicine, New Orleans, LA. American Association for Automotive Medicine. 237-253; 1987.

Rutherford, W. H.; Greenfield, T.; Hayes, H. R. M.; Nelson, J. K. The medical effects of seat belt legislation in the United Kingdom. London: Her Majesty's Stationary Office; 1985.

Schramm, C.; Gabel, J. Prospective payment. N. Engl. J. Med. 318:1681-1683; 1988.

States, J. D.; Ingersoll, G. L.; Annechiarico, R. P.; Carleen, E. D.; Good, R. G.; Licou, J.; Marcsca, B. C. The effect of the New York State safety belt law on hospital admissions in Monroe (Rochester) New York. Proceedings of the American Association for Automotive Medicine; October 6-8, 1986.

Streff. F. M.: Wagenaar, A. C.; Schultz, R. H. Reductions in police-reported injuries associated with Michigan's Safety Belt Law. J. Safety Res. 22:9-24; 1990.

Verway, D. I. (ed). Michigan Statistical Abstract. Detroit: Wayne State University; 1986-1987.

Viano, D. C. Limits and challenges of crash protection. Accid. Anal. Prev. 20:421-429; 1988.

Wagenaar, A. C. Effects of macroeconomic conditions on the incidence of motor vehicle accidents. Accid. Anal. Prev. 16:191-205; 1984.

Wagenaar, A. C.; Maybee, R. G.; Sullivan, K. P. Mandatory seat belt laws in eight states: A time-series cvaluation. J. Safcty Res. 19:51-70; 1988.

Wagenaar, A. C.; Streff, F. M. Macroeconomic conditions and alcohol-impaired driving. J. Stud. Alcohol. 50:217-225; 1989.

Wagenaar, A. C.; Wiviott, M. B. T. Effects of mandating seatbelt use: A series of surveys on compliance in Michigan. Public Health Rep. 101(5):505-513; 1986.

Williams, A. F.; Preusser, D. F.; Blomberg, R. D.; Lund, A. K. Seat belt use law enforcement and publicity in Elmira, New York: A reminder campaign. Am. J. Public Health. 77:1450-1451; 1987.

Wolfe, R. A.; Griffith, J. R.; McMahon, L. F., Jr.; Tedeschi, P. J.; Petroni, G. R.; McLaughlin, C. G. Patterns of surgical and nonsurgical hospital use in Michigan communities from 1980-1984. Health Serv. Res. 24:67-82; 1989.

\section{APPENDIX}

\begin{tabular}{|c|c|c|c|}
\hline \multicolumn{4}{|c|}{ Time-series models } \\
\hline \multicolumn{4}{|c|}{ 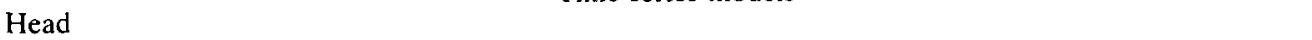 } \\
\hline Frequency & LnY, & $=$ & $3.47+(1+.15 \mathrm{~B})\left(1-.26 \mathrm{~B}^{15}\right) \mathrm{a}_{t}-.002 \mathrm{X}_{\mathrm{t}}$ \\
\hline Rate & $(1-B) \operatorname{Ln} Y_{1}$ & $=$ & $(1-.70 \mathrm{~B})\left(1-.34 \mathrm{~B}^{6}\right) \mathrm{a}_{\mathrm{t}}-.14 \mathrm{X}_{\mathrm{t}}$ \\
\hline \multicolumn{4}{|r|}{ 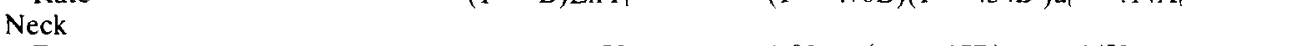 } \\
\hline Frequency & LnY, & $=$ & $1: 90+(1+.17 \mathrm{~B}) \mathrm{a}_{1}+.14 \mathrm{X}_{\mathrm{t}}$ \\
\hline Rate & $\operatorname{LnY}$ & $=$ & $2.88+(1+.17 \mathrm{~B}) \mathrm{a}_{1}-.12 \mathrm{X}_{\mathrm{t}}$ \\
\hline \multicolumn{4}{|l|}{ Back } \\
\hline Frequency & $\left(1-B^{12}\right) \operatorname{Ln} Y_{1}$ & $=$ & $\left(1-.84 B^{12}\right) a_{t}-.02 X_{t}$ \\
\hline Rate & $\operatorname{LnI}_{1}$ & $=$ & $2.64+a_{t}-.27 X_{t}$ \\
\hline \multicolumn{4}{|l|}{ Thorax } \\
\hline Frequency & $\operatorname{LnY} Y_{1}$ & $=$ & $2.27+\left(1-.21 \mathrm{~B}^{2}\right) \mathrm{a}_{1}+.27 \mathrm{X}_{1}$ \\
\hline Rate & I.nY, & $=$ & $3.25+\mathrm{a}_{\mathrm{t}}-.0098 \mathrm{X}_{\mathrm{t}}$ \\
\hline \multicolumn{4}{|l|}{ Abdomen } \\
\hline Frequency & $\mathrm{LnY}$, & $=$ & $1.50+(1-.25 \mathrm{~B})\left(1-.44 \mathrm{~B}^{10}\right) \mathrm{a}_{4}+.15 \mathrm{X}$ \\
\hline Rate & LnY, & $=$ & $2.47+a_{t}-.16 X_{t}$ \\
\hline \multicolumn{4}{|l|}{ Extremity } \\
\hline Frequency & $\left(1-.29 \mathrm{~B}^{4}\right) \mathrm{LnY}_{1}$ & $=$ & $3.17+\mathrm{a}_{t}+.053 \mathrm{X}_{t}$ \\
\hline Rate & $\left(1-\mathrm{B}^{12}\right) \operatorname{LnY}$ & $=$ & $\left(1-.88 \mathrm{~B}^{12}\right) \mathrm{a}_{t}-.23 \mathrm{X}_{t}$ \\
\hline \multicolumn{4}{|l|}{ Total } \\
\hline Frequency & $\begin{array}{r}\operatorname{Ln} Y_{1} \\
\left(1-R^{12}\right)\end{array}$ & $=$ & $4.45+(1+.24 \mathrm{~B}) \mathrm{a}_{1}+.069 \mathrm{X}_{1}$ \\
\hline Rate & $\left(1-B^{12}\right) \operatorname{LnY}$, & $=$ & \\
\hline
\end{tabular}




\section{APPENDIX (Continued)}

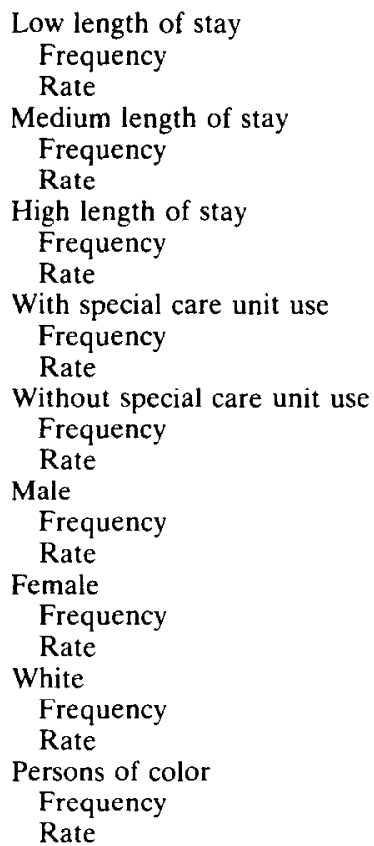

Time-series models

$$
\begin{aligned}
& (1-\mathrm{B}) \operatorname{Ln} \mathrm{Y}_{\mathrm{t}}=(1-.90 \mathrm{~B})\left(1+.22 \mathrm{~B}^{12}\right) \mathrm{a}_{\mathrm{t}}+.15 \mathrm{X}_{\mathrm{t}} \\
& \left(1-\mathrm{B}^{12}\right) \operatorname{Ln} Y_{1}=(1+.25 \mathrm{~B})\left(1-.89 \mathrm{~B}^{12}\right) \mathrm{a}_{\mathrm{t}}+.062 \mathrm{X}_{\mathrm{t}} \\
& \left(1-\mathrm{B}^{12}\right) \operatorname{Ln} Y_{\mathrm{t}}=(1+.27 \mathrm{~B})\left(1-.83 \mathrm{~B}^{12}\right) \mathrm{a}_{\mathrm{t}}+.051 \mathrm{X}_{\mathrm{t}} \\
& (1-\mathrm{B}) \operatorname{LnY}_{\mathrm{t}}=(1-.31 \mathrm{~B}) \mathrm{a}_{\mathrm{t}}+.22 \mathrm{X}_{\mathrm{t}} \\
& \left(1-\mathrm{B}^{12}\right) \operatorname{LnY}=\left(1+.23 \mathrm{~B}^{2}\right)\left(1-.86 \mathrm{~B}^{12}\right) \mathrm{a}_{1}-.28 \mathrm{X}_{\mathrm{t}} \\
& \left(1-\mathrm{B}^{22}\right) \mathrm{LnY}_{\mathrm{t}}=\left(1+.39 \mathrm{~B}+.31 \mathrm{~B}^{2}\right)\left(1-.87 \mathrm{~B}^{12}\right) \mathrm{a}_{\mathrm{t}}-.56 \mathrm{X}_{t} \\
& \operatorname{LnY_{1}}=2.37+\mathrm{a}_{1}+.084 \mathrm{X}_{1} \\
& \operatorname{LnY} Y_{t}=3.35+a_{t}-.18 X_{1} \\
& \left(1-\mathrm{B}^{12}\right) \operatorname{Ln} Y_{1}=\left(1+.23 \mathrm{~B}+.27 \mathrm{~B}^{2}\right)\left(1-.89 \mathrm{~B}^{12}\right) \mathrm{a}_{1}+.072 \mathrm{X}_{1} \\
& (1-\mathrm{B}) \operatorname{LnY_{1}}=\left(1-.25 \mathrm{~B}-.25 \mathrm{~B}^{6}\right) \mathrm{a}_{\mathrm{t}}-.069 \mathrm{X}_{\mathrm{t}} \\
& \left(1-\mathrm{B}^{12}\right) \operatorname{Ln} Y_{t}=\left(1-.17 \mathrm{~B}^{6}\right)\left(1-.86 \mathrm{~B}^{12}\right) \mathrm{a}_{\mathrm{t}}+.077 \mathrm{X}_{\mathrm{t}} \\
& (1-\mathrm{B}) \operatorname{LnY} \mathrm{Y}_{\mathrm{l}}=\left(1-.54 \mathrm{~B}-.39 \mathrm{~B}^{3}\right) \mathrm{a}_{\mathrm{t}}-.15 \mathrm{X}_{\mathrm{t}} \\
& \left(1-\mathrm{B}^{2} \mathrm{LnY}_{1}=\left(1-.76 \mathrm{~B}-.21 \mathrm{~B}^{4}\right) \mathrm{a}_{\mathrm{t}}+.06 \mathrm{X}_{1}\right. \\
& (1-\mathrm{B}) \mathrm{LnY}_{1}=(1-.69 \mathrm{~B})\left(1-.27 \mathrm{~B}^{4}\right)\left(1-.37 \mathrm{~B}^{6}\right) \mathrm{a}_{\mathrm{t}}-.098 \mathrm{X}_{\mathrm{t}} \\
& \left(1-\mathrm{B}^{12}\right) \mathrm{LnY}_{1}=\left(1+.11 \mathrm{~B}-.17 \mathrm{~B}^{5}\right)\left(1-.88 \mathrm{~B}^{12}\right) \mathrm{a}_{1}+.029 \mathrm{X}_{1} \\
& (1-\mathrm{B}) \mathrm{LnY}_{1}=\left(1-.46 \mathrm{~B}-.22 \mathrm{~B}^{4}-.26 \mathrm{~B}^{6}\right) \mathrm{a}_{t}-.22 \mathrm{X}_{\mathrm{t}} \\
& \operatorname{LnY}_{1}=2.06+a_{t}+.021 X_{1} \\
& \operatorname{LnY}_{1}=3.04+a_{1}-.24 X_{1}
\end{aligned}
$$

